Vol.3, No. 3, September 2021, pp. 137-140, doi.org:10.52567/pjsr.v3i3.234

www.pjsr.com.pk

\title{
COMMERCIALIZATION COVERT APPROACH AND TOURISM
}

\author{
Junaid Bashir \\ Assistant Professor, Department of Tourism \& Hospitality, \\ Foundation University, Rawalpindi. \\ Anas Mahmud Arif \\ Assistant Professor, Department of Tourism \& Hospitality, \\ Hazara University Mansehra, Khyber Pakhtunkhwa. \\ Owais Khan \\ PhD Scholar, Department of Archaeology, \\ Hazara University Mansehra, Khyber Pakhtunkhwa.
}

\begin{abstract}
Media has developed a capability to influence the modern world to think/behave in a certain direction, casting a huge impact among new generation as recent studies have shown that the new generation has started neglecting critical and social aspects of life. Children have started to engage themselves in smartphones and games, and have lost their interest in physical activities and communicating skills. In the past, families used to plan their visits to the touristic attractions and museums/monuments along with children being more excited than anyone else, but with the invention of online gaming and other attractions at the ease of accessibility at home, this trend is changing, impacting the collective decisions for use of spare time preferring in-house activities rather plan visits to outdoor attractions. The new generation started throwing tantrums and anger issues which were not evident prior to this technological revolution. Children are bombarded with modern technology which cast negative impact in the minds of the children as the kids of this generation are more regularly in contact with technology and gadgets. The technological advancement in media is changing the lifestyles, thought processes, and somehow isolating us to the inner selves, preventing to enjoying the nature oriented outer world and tourism. Technology generation observe human emotions in a mechanical way at a very young age and hence eventually develop these traits.
\end{abstract}

Keywords: Materialistc Approch, Values, Children behavior, Media impact, Culture, Tantrum/ Frustration

\section{INTRODUCTION}

Media and commercials have taken away the childhood of children. The efforts of parents in the upbringing of children have been minimized (Kirkorianet al., 2008). Media has affected the health of children, their development, and their relation with parents. Media has become so strong that it has easily influenced the lives of children while broadcasting fascinated content that is far away from reality. This virtual content fascinates the children and they became detach from their parents at this critical nurturing age (Jaglom \& Gardner, 1981). Media tricks and traps children to buy their advertisement products without thinking pros and cons of them. If children don't get to buy these products, they get inferiority complex. Media try to rules over the child's mind by emotionally manipulating him. This technique is much effective on children because they aren't able to decode media lies, whereas adults are much familiar with media cunning role (Schmitt et al., 2003). Children have become more materialistic, and commercials and media have taken advantage of that. Indeed, commercial products have become the need of children. Hence, it has become impossible to survive without their strong influence.

LITERATURE REVIEW Communal Recklessness 
Nowadays, children, even preschoolers are so engaged with social media that it's not easy for adults to look after them. Children have contact with mobile phones and social networks on regular basis where they spend most of their time, and put their data on these sites which makes it easy for the interested person to approach them via emailing or text messaging. Some of the children got abused for commercial purposes. Tons of websites trap children to buy their products. Children now prefer to go to shopping malls rather than visiting a zoo and playing physical games. The priorities have changed for the children from outdoor acticities to Indoor activities. They like to go to eat fast foods and look for gadgets in shopping malls. These children prove to be a great customer base for the business community. Our children spend enormous money buying electronics and toys each year, losing interest in the visits of toursist places.

A survey was conducted in the local schools of Khyber Pakhtunkhwa on 550 students of age 8 to 18. Their habits, hobbies, how much money they have, and how they spend it were observed. It was seen that 50 percent of the students spent their money on snacks, beverages and food. They also spent their money on computer games, toys and stickers. The advertising companies likely to target children because they seem more liable to buy their products as they easily get fascinated. This survey also claimed that children from 8 to 18 are consuming these products and this rate is growing every day. It was seen that children benefit the marketing companies very much and this trend doubles each year. It is also observed that children under 16 years of age have a similar taste of choosing products as their peers, and this benefits the companies because they sell tons of products to their consumers in this way.

\section{RESULTS}

\section{Media impact over children needs and desires}

Parents are concerned about keeping their children happy, so they are forced to buy such products that make their children happy. Parents don't even care about the money; they just want their kids to be happy. In this way, advertising companies find an obsessive consumer. The parents admit that they buy such products under the influence of their children; the parents buy these products because their children saw those product in commercials and they want it. Children's desires impact parents' choice not only in terms of buying toys but in other products too. Hence advertising companies focus on children to sell their products effectively (Kunkel, 1988).

Another survey was conducted in which habits, movements and communication skills of children were observed. They were asked questions about shopping malls, fast food restaurants and were observed their to see the way they behave after looking at certain products. Children were observed to understand their priorities and responses towards different commercials. This fact can't be denied that advertisements have become a specialized industry. According to a survey, children are exposed to many advertisements daily. These companies give the impression that life is all about shopping. Attempts were also made to protect the children less than ten years from aggressive commercials that made them violent and selfcentered.

Unfortunately, the new generation is now more into commercialism. Young generation, as a result of media and advertisements, consume modern products more than anyone else. Consumer companies have the main purpose of selling their accessories without realizing that this is damaging our youth which would finally result in their destructive decline. Children have left healthy activities and they are more liable to spend their time at home in front of the television (Flavell, 1990). This research has proved that this generation is quite different from previous one. Advertising companies know tricks to captivate their clients to buy their products. They claim that if children didn't buy their products, they won't be cool enough to survive among their peers, which is not true. These companies are now successfully taking over the market in a very short time. Most of the time, children don't even learn anything from these commercials and video games, and their vocabulary and knowledge suffers. Also, there are number of children who are diagnosed with bipolar disorder, and in addition to that, there is an increase in anxiety and depression issues among children. Parents mostly think that if they didn't purchase such expensive toys for their children, they would suffer from inferiority complex. 


\section{Commercialization Covert Approach and Tourism}

Today, due to the development of malls and shopping centers, the children want to have it all, and it has affected the children's mental capacity in a negative way. The children have developed a trait in which the children tend to start crying and throwing tantrums in the mall or express their rage in other ways. To this particular behavior, the parents start reacting with fear and discomfort which eventually leads to the child getting whatever he or she wants, which in most cases are expensive toys (Florence, 2014).

The expensive toys don't leave a good impression on children. They get violent by playing video games; receive immoral messages in their chat boxs. They don't learn anything productive from these games and toys. Recently, a mobile game was introduced for children between the ages 4 to 10; the game had a girl in it who robs a bank and steals gold bars. This game can leaves a bad impression on children's minds to steal and get into crimes. It reflects the reason of increasing bipolar disorders and imitates periods of depression and elevated mood among children. The antisocial personality disorder disregards moral values and societal norms because of lack of empathy and impulse control. It results in hurting others, being aggressive, breaking laws and do not show any remorse or responsibility.

There is no educational message for the children to follow instead their minds are tainted by these immoral messages conveyed by the advertising companies. These toys and messages also give rise to gender discrimination i.e, pink toys are for girls and boys can't play with those, while blue is for boys which girls are not supposed to play with. It's also considered that girls have the only job to take care of the house, make food and become good wife. And this concept is clearly observed in the toys that girls play with i.e, kitchen sets, cooking sets etc. Likewise, girls are brought barbie doll with its accessories like clothes, shoes, vacuum cleaner, kitchenware, etc. On the other hand, toys for boys are cars, superheroes, and certain electronic toys that helps to develop a logical mind and give rise to creativity. Hence, the message conveyed by companies is that boys have to be intelligent, capable, and powerful, while girls have to look for the house and do chores only. Hence, gender stereotyped messages are sent through these toys.

Now, barbie dolls are outdated and new dolls with half naked dresses and totally unsuitable for a child to play with are introduced in markets. Even though fairytales have been circulating for a century, children still find it fascinating, and modern versions of the same stories appear regularly on television with minor changes. There are many fairytales that are shown to the children in cartoons. They are not helpful in developing their minds rather these concepts are harming the kids mentality. The stories take the children in such imaginations that are impossible to achieve. The cartoonists exaggerate certain points that children take seriously. Hence, fairytales are also a source of delivering immoral messages to children.

Aside from being immoral, toys also convey controversial messages. Crying and talking dolls also exist which are popular among children. The children found it fascinating that the dolls could speak words like mum and dad or show emotions like laughing or crying or move and blink their eyes. As time passes, the dolls became more sophisticated and got lablled with any nation or religion. Such as dolls intended for Muslims are introduced with head Scarbes, and and the dolls could speak Muslim names, such as Amina, and they would introduce themselves as Muslims in mechanic voice. Today's technology has improved the toys for children as modern technology has become a part of the children's toys and has also raised the price, but the price has apparently not bothered the market rather increase the demand. Toys combined with mobile apps have made great success.

\section{CONCLUSION}

Over the years, media and advertising companies have taken over the lives of the new generation and pulled them away from tourism, sports and healthy activities. It promotes the ease of access to enjoy at home with laziness instead to engage in healthy outdoor activities which include tourism. Parents find it easy to provide children the gadgets rather putting efforts of going out and spending time. Increased purchasing power, busy life, inclination towards easiness and shortcuts encourage people to rely on technology, gadgets and media. Media and their advertising companies have influenced the lives of young generation and parents have to bow before their children's desires. The question arises that if a five year- 
old kid can control and have such a strong influence on his parents then what would happen when they grow old.

Parents certainly buy these technologies and gadgets to make their children happy but they are certainly unaware that they have to play strong role in personality development of their children. Also, parents can contribute in the mental development of their children rather than these toys. It has been observed that the children at the age of one and two develop their brains; hence, parents, grandparents and other fellows influence them a lot. They can work best in grooming the child at his earliest age. These interactions are more effective and children learn much more from parents than any other educational institute. This is also true that social media and other technologies have changed the way of thinking in children.

Unfortunately, in the modern world, we can only dream that our children could realize the experience of self-amusement or the joy of playing with fellows and outdoor activities. We have isolated them in a room where they don't talk to anyone and don't learn anything. Today's generation has become materialistic as they are offered gadgets and technology that detached them from their parents, society and the nature.

Children have forgotten their moral and social values. Though, advertising companies claim that they positively spread knowledge and groom children, but they only care about their publicity and profit. They find children to be a soft target who can push adults to buy their products. It is becoming difficult for parents to get away from the strong influence of commercials and advertisements. These companies trap children in their fascinations that are impossible to achieve, left parents helpless. Some people are trying hard to save children from such cosumer products while aiming to make children think critically and decide their destiny by themselves. The new generation is under pressure for performance and the concept of intrinsic value addition is now a long lost idea - when browsing the internet and using cell phone seems as a natural need. Reading a book in a quiet corner of a library has become an archaic idea. This concept diverts the direction of education and changed the route to the materialistic slant.

Though, Modern technology has improved the quality of life but we must make better use of it and provide quality technical support and guidance to our generation. In this way, the children would be given better education and would get engage in healthy activities. Parents need to guide their children about their aim and real purpose in life as in this way, they would be able to set their standards. Children should be taught to use technology and media in a better way so that they could improve their expression and achieve their set goals. Parents building up strong bond with children can play an important role in establishing a quality relationship with them.

Hence, outdoor games and study tours should be part of the educational curriculum in the educational institutes. It helps to build communication skills, better listening, love for nature, and broaden the child's mind. The care for environment, love for nature and seeing the wold around us can balance the attitude, anxiety and depression disorder amongst the youngsters.

\section{REFERENCES}

Flavell, J.H. (1990) Do Young Children Think of Television Images as Pictures or Real Objects? Journal of Broadcasting and Electronic Media, 34.

Florence, U. (2014). Impact of Social Media on Children, Adolescents and Families. Global Journal of Interdisciplinary Social Sciences, 3(2).

Kirkorian' H.L, Wartella, E.A \& Anderson, D.R. (2008). Media and Young Children's Learning. Future Child,18(1), 39-61.

Jaglom, L.M., \& Gardner, H. (1981). The preschool television viewer as anthropologist. New Directions for Child and Adolescent Development, 9-30.

Kunkel, D. (1988). Children and Host-Selling Television Commercials. Communication Research, 15(1), 79-82.

Schmitt, K., Woolf, K.D., Anderson, D.R. (2003). Viewing the Viewers: Viewing Behaviors by Children and Adults during Television Programs and Commercials. Journal of Communication, 53(2), 265 $-281$ 